\title{
Genetic resistance determinants to fusidic acid and chlorhexidine in variably susceptible staphylococci from dogs
}

\author{
S-M Frosini ${ }^{1 *}\left(\mathbb{D}\right.$, R. Bond ${ }^{1}$, M. Rantala ${ }^{2}$, T. Grönthal ${ }^{2}$, S. C. Rankin ${ }^{3}$, K. O'Shea $^{3}$, D. Timofte ${ }^{4}$, V. Schmidt ${ }^{4}$, \\ J. Lindsay ${ }^{5}$ and A. Loeffler ${ }^{1}$
}

\begin{abstract}
Background: Concern exists that frequent use of topically-applied fusidic acid (FA) and chlorhexidine (CHX) for canine pyoderma is driving clinically relevant resistance, despite rare description of FA and CHX genetic resistance determinants in canine-derived staphylococci. This study aimed to determine minimum inhibitory concentrations (MICs) and investigate presence of putative resistance determinants for FA and CHX in canine-derived methicillinresistant (MR) and -susceptible (MS) staphylococci. Plasmid-mediated resistance genes (fusB, fusC, fusD, gacA B, smr; PCR) and MICs (agar dilution) of FA and CHX were investigated in 578 staphylococci (50 MR S. aureus [SA], 50 MSSA, 259 MR S. pseudintermedius [SP], 219 MSSP) from Finland, U.S.A., North (NUK) and South-East U.K. (SEUK) and Germany. In all isolates with FA MIC $\geq 64 \mathrm{mg} / \mathrm{L}(n=27)$ fusA and fusE were amplified and sequenced.

Results: FA resistance determinants (fusA mutations $n=24$, fusB $n=2$, fus $C n=36$ ) were found in isolates from all countries bar U.S.A. and correlated with higher MICs ( $\geq 1 \mathrm{mg} / \mathrm{L})$, although $4 \mathrm{SP}$ isolates had MICs of $0.06 \mathrm{mg} / \mathrm{L}$ despite carrying fusC. CHX MICs did not correlate with qacA/B $(n=2)$ and $\operatorname{smr}(n=5)$, which were found in SEUK SA, and SP from NUK and U.S.A.

Conclusions: Increased FA MICS were frequently associated with fusA mutations and fusC, and this is the first account of fusB in SP. Despite novel description of qacA/B in SP, gene presence did not correlate with CHX MIC. Selection pressure from clinical use might increase prevalence of these genetic determinants, but clinical significance remains uncertain in relation to high skin concentrations achieved by topical therapy.
\end{abstract}

Keywords: Staphylococci, Canine, Fusidic acid, Chlorhexidine, Resistance, Veterinary

\section{Background}

Coagulase-positive staphylococci, primarily Staphylococcus pseudintermedius and less often S. aureus and S. schleiferi, are the predominant pathogens in canine superficial pyoderma [1]. The emergence of methicillin-resistant strains of S. pseudintermedius (MRSP), that are usually resistant to most or all available licensed systemic veterinary antimicrobials [2, 3], has increased interest in the use of topical therapy [4], most commonly with products that contain fusidic acid or chlorhexidine [5]. These same antimicrobials are used topically in human medicine, but in people fusidic

\footnotetext{
*Correspondence: sfrosini@rvc.ac.uk

'Department of Clinical Sciences and Services, Royal Veterinary College, Hawkshead Lane, North Mymms, Hatfield, Hertfordshire AL9 7TA, UK Full list of author information is available at the end of the article
}

acid is also used systemically as a last line treatment option for bacteraemia caused by methicillin-resistant $S$. aureus (MRSA) [6].

Infections caused by methicillin-susceptible (MS) and MRSP have been documented in humans [7-10], and zoonotic transmission of MSSP and MRSP has been inferred by the isolation of genetically identical MRSP isolates from pet dogs and their infected human owners [11]. Similarly, occasional human nasal carriage of MSSP and even MRSP has been described [12-14], again with indistinguishable pulsed-field gel electrophoresis (PFGE) patterns to those carried by in-contact pet dogs $[15,16]$.

Topical therapy with fusidic acid is common in human medicine for staphylococcal skin infections and is also recommended [17] and used in dogs with skin infections, at

C The Author(s). 2019 Open Access This article is distributed under the terms of the Creative Commons Attribution 4.0 International License (http://creativecommons.org/licenses/by/4.0/), which permits unrestricted use, distribution, and 
least in European countries but not in the U.S.A. Chlorhexidine is used worldwide as a disinfectant and antiseptic, and in topical antibacterial products for dogs. Whilst topical antibacterial therapy is recommended as an alternative to systemic treatment [4] in order to reduce selection pressure on pathogens, there are concerns over reduced phenotypic susceptibility to these agents $[18,19]$. In New Zealand, clonal expansion of fusidic acid-resistant $S$. aureus (based on disk diffusion testing) was reported concurrently with a significant increase in national dispensing of topical fusidic acid products for humans [20]. By contrast, the prevalence of phenotypic resistance to fusidic acid (minimum inhibitory concentration $[\mathrm{MIC}] \geq 1 \mathrm{mg} / \mathrm{L}$ determined using VITEK 2) [21] increased amongst MRSA in the U.K. despite stable (2002-2009) and decreasing (2009-2013) fusidic acid sales [22]. Reduced susceptibility of MRSA to chlorhexidine following increased antiseptic use was demonstrated in human hospitals [19, 23, 24]; the presence of genetic characteristics thought to be related to reduced chlorhexidine susceptibility has also been implicated in failure of decolonisation strategies [25].

The acquired resistance genes fusB [26-28], fusC [27-29] and fusD $[28,29]$, most commonly carried on plasmids, and chromosomal mutations in fusA [27, 28, 30,31] and fusE $[28,31]$ have been associated with reduced susceptibility to fusidic acid in S. aureus. Geographical variation in the presence of these genes in phenotypically fusidic acid-resistant $S$. aureus derived from humans, defined by clinical breakpoints, has been described [28, 32-34]. In $S$. pseudintermedius, there is one publication that describes fusA mutations conferring fusidic acid resistance in a single isolate [35], and only two isolates of $S$. (pseud)intermedius have been shown to carry fusC [29], despite widespread licensing and marketing of fusidic acid products for topical use in small animal veterinary practice in Europe during the past four decades.

Plasmid-derived $q a c A / B$ and $s m r$ have an uncertain correlation with reduced susceptibility to chlorhexidine amongst staphylococci [36-41]. Transfer of $q a c A / B$ by transduction between isolates of $S$. aureus has been described, although the effect of this transfer on susceptibility to chlorhexidine was not assessed [42]. Whether transfer of resistance genes can occur between S. pseudintermedius and $S$. aureus still remains unclear but evidence for such transfer between staphylococcal species exists [43], most notably of the SCCmec (predominantly type IV) which encodes methicillin resistance and is believed to have originated in coagulase-negative staphylococci [44-47]. An increase in the prevalence of resistance genes in canine-derived staphylococci due to veterinary use of topically-applied antimicrobials could become of concern to veterinarians if clinical failure occurred. Furthermore, there could be implications for both human and canine health through either transfer of resistant strains between hosts, or of genetic material to susceptible bacterial species. This study investigated the association between resistance genes and MICs of fusidic acid and chlorhexidine in canine-derived S. pseudintermedius and S. aureus in a large collection of isolates obtained from wide geographical areas.

\section{Results}

The MICs (new and previously determined), $\mathrm{MIC}_{50}$, $\mathrm{MIC}_{90}$ values and comparisons between regional groups are detailed in Fig. 1 and Tables 1 and 2.

The MICs of fusidic acid specifically determined for this study for S. pseudintermedius $(n=339)$ from NUK, Finland and the U.S.A ranged from 0.03 to $>64 \mathrm{mg} / \mathrm{L}$. In the 40 Finnish FA-R MRSP the lowest MIC was $4 \mathrm{mg} / \mathrm{L}$. Of the remaining 299 isolates, 76 had MIC $\geq 1 \mathrm{mg} / \mathrm{L}$ (43 NUK, 31 Finland, 2 U.S.A) while 223 isolates were phenotypically fusidic acid-susceptible based on EUCAST breakpoints [21] (Table 1). The MICs of reference isolates were low (ATCC $25923^{\text {max }}$ and LMG 22219, $0.06 \mathrm{mg} / \mathrm{L}$; ATCC $29663^{\mathrm{mix}}, 0.03$ $\mathrm{mg} / \mathrm{L}$ ), consistent with previous reports $[48,49]$. Chlorhexidine MICs of Finnish and U.S.A. isolates $(n=200)$ ranged from 0.25 to $4 \mathrm{mg} / \mathrm{L} ; 196$ isolates had MICs of 0.5 or $1 \mathrm{mg} / \mathrm{L}$ (1 Finnish MRSP, $0.25 \mathrm{mg} / \mathrm{L} ; 1$ U.S.A. MSSP, $2 \mathrm{mg} / \mathrm{L} ; 1$ Finnish MRSP and 1 U.S.A. MSSP, $4 \mathrm{mg} / \mathrm{L}$; Table 2). The MICs for fusidic acid and chlorhexidine did not differ between MRSP and MSSP within groups of isolates from each country (fusidic acid U.S.A., Germany, SEUK $P=1.000$, Finland $P=0.408$; chlorhexidine U.S.A, Finland, SEUK $P=1.000$, Germany $P=0.152$ ) except in the NUK ( $P<0.005$ for both fusidic acid and chlorhexidine).

Twenty-seven of all 578 staphylococci, had fusidic acid $\mathrm{MIC} \geq 64 \mathrm{mg} / \mathrm{L}$ and thus underwent fusA and fusE sequencing (5 MRSA SEUK, 4 MSSP NUK, 4 MRSP NUK, 1 MRSP SEUK, 1 Finnish MRSP, 12 Finnish FA-R MRSP). All eight internal primers designed to sequence the 2100 bp product of fusA aligned to S. pseudintermedius. Although two primers (FusA_Int_D_F and FusA_Int_F_R; Table 3) did not align with $S$. aureus isolates, the whole gene sequence was obtained using the remaining six primers in 3 / 5 MRSA isolates. In the remaining two MRSA isolates, mutation analyses were prevented by failure to amplify fusA.

Of the remaining 25 isolates with an MIC $\geq 64 \mathrm{mg} / \mathrm{L}$ (3 MRSA, 4 MSSP NUK, 4 MRSP NUK, 1 MRSP SEUK, 1 Finnish MRSP, 12 Finnish FA-R MRSP), 24 had at least one fusA mutation (Table 4); one MRSA isolate had none. All mutations observed represented non-conservative substitutions (Table 4). No fusE mutations were detected in any of the tested isolates (fusidic acid MIC $\geq 64 \mathrm{mg} / \mathrm{L}$ ).

Of the plasmid-mediated fusidic acid resistance genes, fus $B$ and fus $C$ were detected in the collection but fus $D$ was not (Table 1). In S. pseudintermedius, fusB was detected in 2 isolates (5\%) of the Finnish FA-R MRSP; fus $B$ 


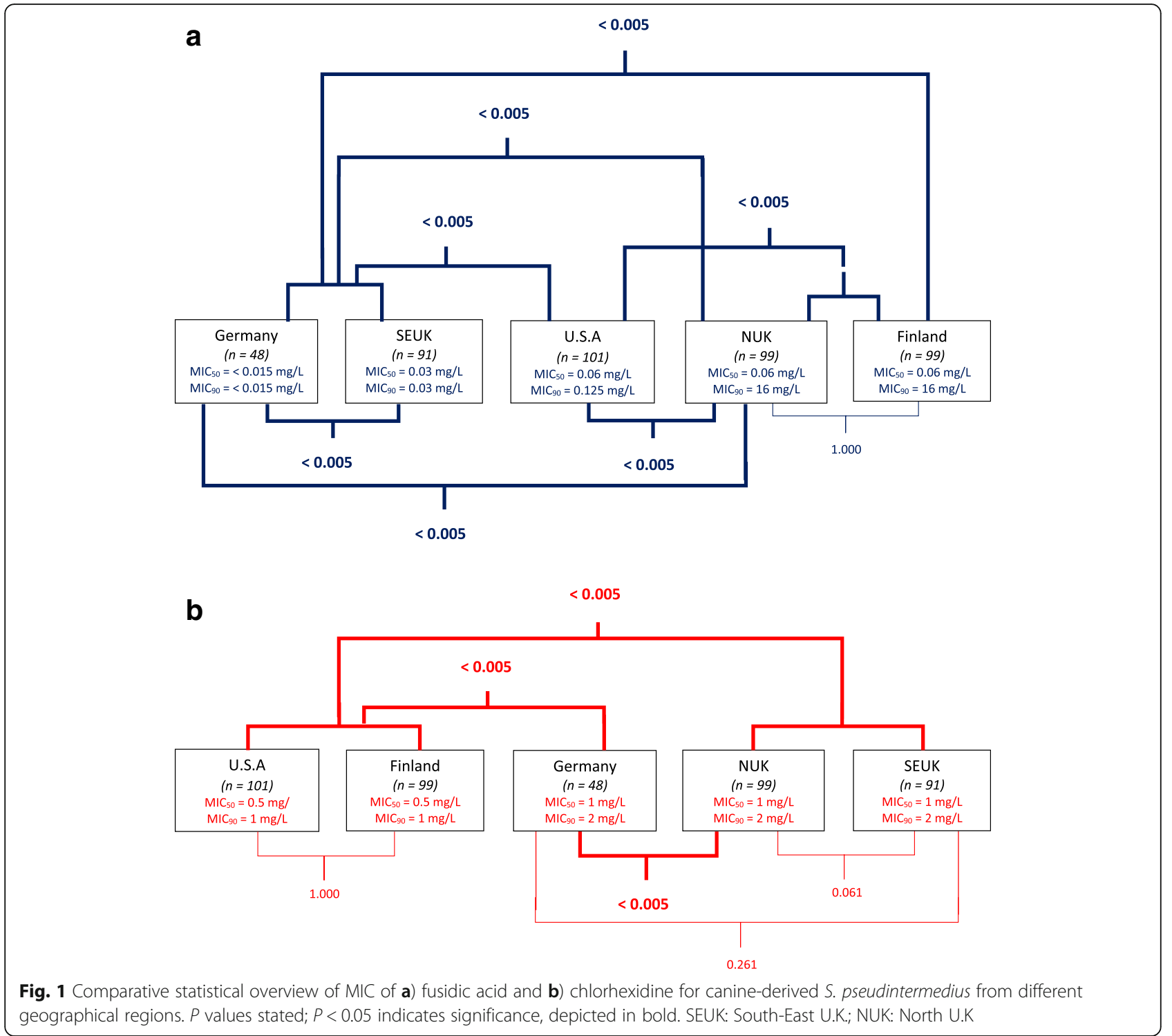

was not detected in isolates from any other region, nor in $S$. aureus. In Finnish $S$. pseudintermedius, fus $C$ was quite regularly detected (13/40 FA-R MRSP, 9/49 MRSP, 5/50 MSSP), as well as being found in 7/49 NUK MRSP. It was not detected in $S$. pseudintermedius from any other region. In $S$. aureus, fus $C$ was detected in $2 / 50$ SEUK MSSA.

Both fusB carrying isolates had MICs of $8 \mathrm{mg} / \mathrm{L}$ (Table 1). In 32 isolates (89\%) carrying fusC, the fusidic acid MIC was 4-16 mg/L (Table 1). However, the other four isolates carrying fusC (1 NUK MRSP, 2 Finnish MRSP, 1 Finnish MSSP) had a fusidic acid-sensitive phenotype (MIC $=0.06$ $\mathrm{mg} / \mathrm{L}$ ) (Table 1).

The only MRSA isolate with a fusidic acid MIC of 64 $\mathrm{mg} / \mathrm{L}$ that had no mutation in either fusA or fusE, did not carry fusB, fus $C$ or fusD either. Similarly, 51 isolates
(1 MSSA, 34 MRSP, 16 MSSP) with 'low-level' fusidic acid resistance (MIC 4-16 mg/L) [28] did not carry fusB, fusC or fusD.

The chlorhexidine resistance determinants $q a c A / B$ and smr were not detected in any isolates from Germany or Finland, nor in S. pseudintermedius from SEUK (Table 2). In S. pseudintermedius from the U.S.A., 3/50 MRSP isolates and 1/51 MSSP isolates carried the $s m r$ gene; 1 NUK MSSP isolate (out of 50) carried $q a c A / B$. In $S$. aureus (all SEUK), 1 MSSA carried $q a c A / B$ and 1 carried $s m r$. Presence of $s m r$ related to chlorhexidine MICs of $0.5-4 \mathrm{mg} / \mathrm{L}$ and presence of $q a c A / B$ related to chlorhexidine MICs of $2-4 \mathrm{mg} / \mathrm{L}$ (Table 2).

No single isolate carried more than one of the resistance determinants investigated. 
Table 1 Minimum inhibitory concentrations (MICs) of fusidic acid determined by agar dilution, and presence of resistance determinants, for canine-derived Staphylococcus pseudintermedius and S. aureus isolates $(n=578)$ from Finland, the U.S.A., North U.K. (NUK), South-East U.K. (SEUK) and Germany

\begin{tabular}{|c|c|c|c|c|c|c|c|c|c|c|c|c|c|c|c|c|c|c|}
\hline \multirow[t]{2}{*}{ Country } & \multirow{2}{*}{$\begin{array}{l}\text { Bacterial } \\
\text { Type }\end{array}$} & \multirow[t]{2}{*}{$\mathrm{n}$} & \multicolumn{14}{|c|}{ Fusidic acid MIC (mg/L) } & \multirow{2}{*}{$\begin{array}{l}\mathrm{MIC}_{50} \\
(\mathrm{mg} / \mathrm{L})\end{array}$} & \multirow{2}{*}{$\begin{array}{l}\mathrm{MIC}_{90} \\
(\mathrm{mg} / \mathrm{L})\end{array}$} \\
\hline & & & $\leq 0.015$ & 0.03 & 0.06 & 0.125 & 0.25 & 0.5 & 1 & 2 & 4 & 8 & 16 & 32 & 64 & $>64$ & & \\
\hline \multirow[t]{3}{*}{ Finland } & MRSP & 49 & 0 & 0 & $\begin{array}{l}28 n= \\
2 \text { fusC }\end{array}$ & 0 & 0 & 0 & 0 & 3 & $\begin{array}{l}5 n=4 \\
\text { fusC }\end{array}$ & $4 n=2$ fus $C$ & $\begin{array}{l}8 n= \\
1 \text { fusC }\end{array}$ & 0 & $\begin{array}{l}1 \mathrm{n}=1 \\
\text { fusA }\end{array}$ & 0 & 0.06 & 16 \\
\hline & $\begin{array}{l}\text { FA-R } \\
\text { MRSP }\end{array}$ & 40 & 0 & 0 & 0 & 0 & 0 & 0 & 0 & 0 & $\begin{array}{l}13 n= \\
12 \text { fusC }\end{array}$ & $\begin{array}{l}10 \mathrm{n}=1 \text { fus } C \\
\mathrm{n}=2 \text { fus } B\end{array}$ & 5 & 0 & $\begin{array}{l}12 \mathrm{n}= \\
12 \mathrm{fus} A\end{array}$ & 0 & 8 & 64 \\
\hline & MSSP & 50 & 0 & 1 & $\begin{array}{l}38 n= \\
1 \text { fusC }\end{array}$ & 1 & 0 & 0 & 0 & 0 & 0 & $7 \mathrm{n}=3$ fus $C$ & $\begin{array}{l}3 n= \\
1 \text { fusC }\end{array}$ & 0 & 0 & 0 & 0.06 & 8 \\
\hline \multirow[t]{2}{*}{ U.S.A. } & MRSP & 50 & 0 & 2 & 38 & 10 & 0 & 0 & 0 & 0 & 0 & 0 & 0 & 0 & 0 & 0 & 0.06 & 0.125 \\
\hline & MSSP & 51 & 0 & 0 & 47 & 2 & 0 & 0 & 0 & 0 & 2 & 0 & 0 & 0 & 0 & 0 & 0.06 & 0.06 \\
\hline \multirow[t]{2}{*}{ NUK } & MRSP & 49 & 0 & 0 & $\begin{array}{l}14 \mathrm{n}= \\
1 \text { fusC }\end{array}$ & 4 & 0 & 0 & 0 & 14 & $\begin{array}{l}2 n=1 \\
\text { fus } C\end{array}$ & $10 n=5$ fus $C$ & 0 & 0 & $\begin{array}{l}4 \mathrm{n}=4 \\
\text { fusA }\end{array}$ & 1 & 2 & 64 \\
\hline & MSSP & 50 & 0 & 1 & 37 & 0 & 0 & 0 & 1 & 0 & 1 & 5 & 1 & 0 & $\begin{array}{l}2 \mathrm{n}=2 \\
\text { fusA }\end{array}$ & $\begin{array}{l}2 n= \\
2 \text { fusA }\end{array}$ & 0.06 & 8 \\
\hline \multirow[t]{4}{*}{ SEUK ${ }^{\mathrm{a}}$} & MRSP & 47 & 22 & 1 & 12 & 3 & 0 & 0 & 1 & 2 & 4 & 0 & 1 & 0 & $\begin{array}{l}1 \mathrm{n}=1 \\
\text { fus } A\end{array}$ & 0 & 0.06 & 4 \\
\hline & MSSP & 44 & 19 & 5 & 14 & 1 & 0 & 0 & 2 & 2 & 0 & 1 & 0 & 0 & 0 & 0 & 0.03 & 1 \\
\hline & MRSA & 50 & 8 & 34 & 0 & 0 & 3 & 0 & 0 & 0 & 0 & 0 & 0 & 0 & 1 & $\begin{array}{l}4 n= \\
2 \text { fusA }\end{array}$ & 0.03 & 0.25 \\
\hline & MSSA & 50 & 24 & 13 & 0 & 0 & 1 & 1 & 6 & 2 & $\begin{array}{l}2 n=2 \\
\text { fus } C\end{array}$ & 0 & 1 & 0 & 0 & 0 & 0.03 & 1 \\
\hline \multirow[t]{2}{*}{ Germany $^{a}$} & MRSP & 24 & 0 & 0 & 0 & 0 & 0 & 0 & 0 & 0 & 0 & 0 & 0 & 0 & 0 & 0 & $<0.015$ & $<0.015$ \\
\hline & MSSP & 21 & 0 & 0 & 0 & 0 & 0 & 0 & 0 & 3 & 0 & 0 & 0 & 0 & 0 & 0 & $<0.015$ & $<0.015$ \\
\hline
\end{tabular}

EUCAST breakpoint for fusidic acid for staphylococci is $1 \mathrm{mg} / \mathrm{L}$; (reference [62]).

MRSP methicillin-resistant Staphylococcus pseudintermedius, FA-R fusidic acid-resistant, MSSP methicillin-sensitive S. pseudintermedius, NUK North U.K., SEUK South-East U.K, MRSA methicillin-resistant S. aureus, MSSA methicillin-susceptible S. aureus.

${ }^{\mathrm{a}} \mathrm{MICs}$ determined as part of previous study by the authors (reference [52])

Table 2 Minimum inhibitory concentrations (MICS) of chlorhexidine determined by agar dilution, and presence of resistance determinants, for canine-derived Staphylococcus pseudintermedius and S. aureus isolates $(n=538)$ from Finland, the U.S.A., North U.K. (NUK), South-East U.K. (SEUK) and Germany

\begin{tabular}{|c|c|c|c|c|c|c|c|c|c|c|c|c|}
\hline \multirow[t]{2}{*}{ Country } & \multirow{2}{*}{$\begin{array}{l}\text { Bacterial } \\
\text { Type }\end{array}$} & \multirow[t]{2}{*}{$n$} & \multicolumn{8}{|c|}{ Chlorhexidine MIC (mg/L) } & \multirow{2}{*}{$\begin{array}{l}\mathrm{MIC}_{50} \\
\mathrm{mg} / \mathrm{L}\end{array}$} & \multirow{2}{*}{$\begin{array}{l}\mathrm{MIC}_{90} \\
\mathrm{mg} / \mathrm{L}\end{array}$} \\
\hline & & & 0.125 & 0.25 & 0.5 & 1 & 2 & 4 & 8 & 16 & & \\
\hline \multirow[t]{2}{*}{ Finland } & MRSP & 49 & 0 & 1 & 35 & 12 & 0 & 1 & 0 & 0 & 0.5 & 1 \\
\hline & MSSP & 50 & 0 & 0 & 38 & 12 & 0 & 0 & 0 & 0 & 0.5 & 1 \\
\hline \multirow[t]{2}{*}{ U.S.A. } & MRSP & 50 & 0 & 0 & $35 \mathrm{n}=2 \mathrm{smr}$ & $15 \mathrm{n}=1 \mathrm{smr}$ & 0 & 0 & 0 & 0 & 0.5 & 1 \\
\hline & MSSP & 51 & 0 & 0 & $45 \mathrm{n}=1 \mathrm{smr}$ & 4 & 1 & 1 & 0 & 0 & 0.5 & 1 \\
\hline \multirow[t]{2}{*}{$N^{\prime} K^{b}$} & MRSP & 49 & 0 & 0 & 0 & 16 & 25 & 8 & 0 & 0 & 2 & 4 \\
\hline & MSSP & 50 & 0 & 0 & 0 & 36 & $14 \mathrm{n}=1 \mathrm{gac} A \mathrm{~B}$ & 0 & 0 & 0 & 1 & 2 \\
\hline \multirow[t]{4}{*}{ SEUK ${ }^{a}$} & MRSP & 47 & 0 & 0 & 0 & 21 & 23 & 2 & 1 & 0 & 2 & 2 \\
\hline & MSSP & 44 & 0 & 0 & 1 & 22 & 17 & 2 & 2 & 0 & 1 & 2 \\
\hline & MRSA & 50 & 0 & 0 & 0 & 0 & 0 & 49 & 1 & 0 & 4 & 4 \\
\hline & MSSA & 50 & 0 & 0 & 1 & 22 & 22 & $5 \mathrm{n}=1 \operatorname{qac} A / B \mathrm{n}=1 \mathrm{smr}$ & 0 & 0 & 2 & 2 \\
\hline \multirow[t]{2}{*}{ Germany $^{a}$} & MRSP & 24 & 0 & 0 & 9 & 4 & 11 & 0 & 0 & 0 & 1 & 2 \\
\hline & MSSP & 24 & 0 & 0 & 11 & 13 & 0 & 0 & 0 & 0 & 1 & 1 \\
\hline
\end{tabular}

MRSP methicillin-resistant Staphylococcus pseudintermedius, MSSP methicillin-sensitive S. pseudintermedius, NUK North U.K., SEUK South-East U.K, MRSA methicillinresistant S. aureus, MSSA methicillin-susceptible S. aureus.

${ }^{a}$ MICs determined as part of previous study by the authors (reference [52])

${ }^{\mathrm{b}} \mathrm{MICs}$ determined as part of previous study by the authors (reference [45]) 
Table 3 Six custom primers designed and used for coverage of entire fusA PCR amplicon of staphylococci for Sanger sequencing, alongside previously described forward and reverse primers (reference [34])

\begin{tabular}{|c|c|c|c|}
\hline Primer Name & Primer Sequence & Forward / Reverse & Base pair sequenced from \\
\hline FusA_Int_A_F & CGCCAACTCACGTGAAGAAA & Forward & 1077 \\
\hline FusA_Int_B_R & ATTGACCACGACCACCAGAT & Reverse & 1516 \\
\hline FusA_Int_C_R & TGCTTCACGTGCTTCTTCAG & Reverse & 639 \\
\hline FusA_Int_D_F & CCAATCGGTGCTGAAGATGA & Forward & 493 \\
\hline FusA_Int_E_F & ATCTGGTGGTCGTGGTCAAT & Forward & 1497 \\
\hline FusA_Int_F_R & TGAGTTGGCTGTCATTTGTA & Reverse & 1086 \\
\hline FusA_F ${ }^{a}$ & TTACCCTGAGTGTGTTCT & Forward & 94 \\
\hline FusA_R $R^{a}$ & TACATTTAAGCTCACCTTGT & Reverse & 2256 \\
\hline
\end{tabular}

aPreviously described primers (reference [34])

\section{Discussion}

The same acquired resistance genes (fus $A$ mutations, fus $B$, fus $C, q a c A / B$ and $s m r$ ) that have been previously described in human-derived $S$. aureus [32-34] were found in canine-derived S. pseudintermedius and $S$. aureus in this study. However, for some of these genes, evidence of their association with increased fusidic acid and chlorhexidine MICs remains inconclusive.

For S. aureus, chromosomal mutations in fusA have been shown experimentally to elevate the MIC of fusidic acid by up to 32 -fold [30], causing 'high-level' fusidic acid resistance in clinical isolates. The results from this study now support a previous report on a single isolate [35] that this is also the case for S. pseudintermedius, as fusA mutations were detected in isolates from the SEUK (MRSP), NUK (MRSP and MSSP) and Finland (MRSP). Whether fusA mutations play a role in 'low-level' resistance (MIC 4-16 mg/L) [28] remains to be investigated, particularly since there were 51 isolates with MICs compatible with 'low-level' resistance that did not carry fus $B-D$ [28]. Failure to amplify fus $A$ in two MRSA isolates might reflect mutation(s) at primer-binding sites; this could be evaluated by whole genome sequencing.

The single canine-derived MRSP previously reported with fusA mutations [35], showed substitutions at the same three sites (V90I, A376V and I461V) as those found in 20 of the 24 isolates with fusA mutations in this study. A novel substitution at one of these sites (I461T), likely related to reduced fusidic acid susceptibility, was shown in MRSP from Finland, NUK and SEUK. The other two amino acid substitutions found within fusA during this study (V90I, A376V) were at positions that are conserved between fusidic acid-susceptible $S$. aureus and $S$. pseudintermedius, and mutations at these sites have been previously described in European $S$. aureus [27, 30, 32, 35]. Substitution at position 90 (V - > I) has previously been shown to be unrelated to fusidic acid resistance in S. pseudintermedius when found on its own [35], and could have a compensatory effect to counteract fitness cost associated with other mutations [50]. The novel identification of the same mutations in three MSSP isolates from the NUK could be due to loss of methicillin resistance. This has been previously demonstrated in $S$. aureus, due to fitness costs of carrying some SCCmec cassettes [51,52], and is more likely than an identical set of three single nucleotide polymorphisms arising in a separate lineage. Two canine-derived MRSA in this study had a single mutation (L461K), which has been previously described in human-derived S. aureus [32, 34], reflecting that canine-derived MRSA isolates usually represent transfer of successful human-hospital-associated lineages [53] into the canine population.

This is the first description of fusB in S. pseudintermedius resulting in 'low-level' fusidic acid resistance, in parallel to that previously described in S. aureus [28]. The presence of fusB in a new staphylococcal species suggests that there may have been genetic transfer of plasmids between staphylococci. Previous studies indicate

Table 4 Mutation sites detected in fusA in two methicillin-resistant Staphylococcus aureus (MRSA), 18 methicillin-resistant S. pseudintermedius (MRSP) and 4 methicillin-sensitive S. pseudintermedius (MSSP) isolates

\begin{tabular}{llll}
\hline Amino acid substitution & Nucleotide substitution & No. of isolates & Fusidic acid MIC (mg/L) \\
\hline L461K & TTA - > AAA & 2 (SEUK MRSA) & $384^{\mathrm{a}}$ \\
1461K & ATT - > AAA & 1 (NUK MSSP) & $>64$ \\
V90I / A376V / 1461T & GTA - > ATA / GCA - > GTA / ATT - > ACT & 1 (NUK MSSP) & $>64$ \\
& & 20 ( $n=12$ FA-R Finland MRSP; $n=1$ Finland MRSP, & 64 \\
& & $n=2$ NUK MSSP, $n=4$ NUK MRSP, $n=1$ SEUK MRSP) & \\
\hline
\end{tabular}

MIC minimum inhibitory concentration, SEUK South-East U.K, NUK North U.K.

${ }^{\mathrm{a}} \mathrm{MIC}$ determined as part of previous study (reference [52]) 
that this may be a rare occurrence due to the difference in restriction modification systems amongst staphylococci $[35,54]$. However, the potential for further genetic transfer of resistance determinants between $S$. aureus and S. pseudintermedius, and amongst S. pseudintermedius lineages, as previously shown for mecA amongst staphylococci [44-47], highlights a risk to human health from any increase in resistance in veterinary-derived staphylococci and vice-versa. The presence of the same plasmid-mediated resistance in different species could also be evidence of a common ancestor for these genes (such as fusB and fusC which show protein homology), as has been previously described for the SCCmec of staphylococci [46].

Whilst in the majority of cases the presence of $f u s C$ was related to 'low-level' fusidic acid resistance, as described in $S$. aureus carrying fusC [28], we report, for the first time, four $S$. pseudintermedius isolates with a susceptible phenotype (MIC $=0.06 \mathrm{mg} / \mathrm{L}$ ) despite presence of fusC. This may reflect the fact that in previous studies, the presence of this gene has been investigated only in phenotypically fusidic acid-resistant (fusidic acid MIC $\geq 1 \mathrm{mg} / \mathrm{L}$ ) isolates [32-34]. Phenotypic susceptibility in the presence of fus $C$ could be due to a chromosomal rather than a plasmid location of fusC [55], low copy number of fusC-containing plasmids, or due to non-expression of the gene. It may also question the relevance of fus $C$ in reducing susceptibility to fusidic acid.

The low fusidic acid MICs in canine-derived S. pseudintermedius from the U.S.A. corresponds to its lack of use in veterinary medicine, whereas MICs were higher in isolates from the U.K and Finland which have had licensed fusidic acid available to veterinarians for a number of years. This mirrors the MICs of human-derived staphylococci which tend to reflect fusidic acid use [32, 33]. Although $\mathrm{MIC}_{50}$ remained low in most regions tested (with the exception of NUK MRSP), in our study the identification of genetic resistance determinants correlated with raised $\mathrm{MIC}_{90}$ in isolates from Finland and the U.K., matching the apparently bimodal distribution of MICs above and below a 'resistance' cut-off. The prevalence of fusB and fus $C$ in the European canine-derived staphylococci in this study is broadly comparable to that seen in human-derived $S$. aureus [32], with variation in gene presence between isolates originating from differing European countries.

This study represents the first description of $q a c A / B$ and corroborates previous reports of $s m r$ in S. pseudintermedius [36], and supports recent reports of $q a c A / B$ in canine-derived $S$. aureus isolates, although at lower frequencies than previously identified in human-derived $S$. aureus $(6 \%$ in U.S.A. MRSP in this study, compared to $8.3-63 \%$ previously described) [56-59]. However, neither $q a c A / B$ nor $s m r$ appeared related to high chlorhexidine MICs, similar to what has been described for human-derived $S$. aureus $[38,41]$ and
S. epidermidis [60], and in a limited collection of S. pseudintermedius [36]. This raises the possibility of different, and as of yet unknown, mechanisms being responsible for raised chlorhexidine MICs. Chlorhexidine MICs remained remarkably uniform within the same geographical region, represented by $\mathrm{MIC}_{50} / \mathrm{MIC}_{90}$ within one dilution of each other. Although statistically significant, the difference in the MIC between some geographical regions was no more than one to two dilutions, which is unlikely to represent a clinically significant variation in efficacy of chlorhexidine-based products. The MIC range of chlorhexidine across all geographical regions tested correlated closely with that previously described for S. aureus [37, 38], potentially reflecting relatively uniform use of chlorhexidine-based products globally in both human and veterinary medicine.

The increasing interest in the use of topical therapy for canine pyoderma amidst efforts towards good antimicrobial stewardship has highlighted the absence of clinically relevant breakpoints for topically applied agents, such as fusidic acid and chlorhexidine. The concentrations of fusidic acid obtained within the skin $24 \mathrm{~h}$ after application to a canine skin model (of the order of $2000 \mathrm{mg} / \mathrm{L}$ ) [61], are approximately 1000-fold higher than the EUCAST breakpoint for fusidic acid for staphylococci (derived for systemic administration in humans) [62]. In each of the geographical regions studied, topical fusidic acid therapy would be expected to achieve concentrations in canine skin far exceeding the majority of MICs described in this study [61], despite presence of resistance determinants in the staphylococcal population tested. These observations highlight the questionable relevance of routine susceptibility testing with current conventional protocols when assessing topical treatment options. There is an urgent need for development of breakpoints that might usefully predict antimicrobial efficacy of topically applied drugs in surface and superficial skin infections [63], to prevent the unwary clinician being misled by laboratory application of existing breakpoints, developed for systemic therapy, that leads to reports of 'resistance'.

\section{Conclusions}

Resistance determinants associated with tolerance to fusidic acid (fus $A$ mutations, fusB and fus $C$ ) were detected at a low rate in canine-derived staphylococci in this study. Conversely, the presence of $q a c A / B$ and $s m r$ appeared to have no effect on chlorhexidine MIC. The low fusidic acid MICs and the lack of fusidic acid resistance determinants in isolates from the U.S.A. compared to the other geographical regions was not surprising, given that fusidic acid is not authorised for use in dogs in the U.S.A. In addition, the overall low prevalence of resistance genes in this collection of 578 mostly clinical staphylococcal isolates, and the corresponding low MICs 
for fusidic acid and chlorhexidine, indicate good continued antibacterial efficacy of these agents. Further clinical studies to provide good evidence for in vivo efficacy of these antimicrobials in canine surface and superficial pyoderma should be encouraged. Further investigations are now needed to elucidate further the role of fus $C$, $q a c A / B$ and $s m r$, and to investigate for novel resistance characteristics that may be of relevance to facilitate future resistance monitoring and to guide appropriate use of these valuable agents.

\section{Methods}

\section{Bacterial isolates}

A total of 578 coagulase-positive staphylococci $(100 \mathrm{~S}$. aureus obtained in 2005-07 and 478 S. pseudintermedius obtained in 2010-16) isolated from dogs were included from four countries: U.K. (split into South-East [SEUK] and North [NUK] as previously defined) [48], Germany, Finland and the U.S.A. (Table 5).

All isolates were collected from canine infections (with the exception of SEUK MSSP, which were both clinical and carriage isolates) (Table 5). In order to investigate isolates with a wide range of fusidic acid susceptibility, an extra 40 clinical MRSP from Finland were included (Finnish FA-R MRSP), which had been determined as fusidic acid-resistant by disk diffusion testing (by MR and TG) interpreted using the Finnish FiRe criteria (Table 5) $[64,65]$. Species identification and methicillin resistance were confirmed (by SMF and AL) by both phenotypic [66] and genotypic methods (for species-specific $n u c$ and methicillin resistance mecA) [67-69].

\section{MIC determination}

Fusidic acid and chlorhexidine MICs were determined in duplicate using an agar dilution method (CLSI VET01A4) [70]. Fusidic acid and chlorhexidine MICs for isolates from SEUK and Germany, and chlorhexidine MICS for NUK isolates, have been reported previously $[48,49]$. Stock solutions of fusidic acid sodium salt (F0881, Sigma-Aldrich Inc., Gillingham, U.K.) and chlorhexidine (C9394, Sigma-Aldrich Inc.) at $10 \mathrm{x}$ final concentration, adjusted for drug potency, were prepared in distilled water [70]. Final concentrations of the active fraction ranged from $0.015-64 \mathrm{mg} / \mathrm{L}$ for fusidic acid and 0.125 $64 \mathrm{mg} / \mathrm{L}$ for chlorhexidine, based on previous experience [48, 49]. Discrepancy between the duplicate MICs was accepted, provided they varied by only one dilution; in these cases, the higher value was recorded as the final MIC as a conservative measure. For quality control purposes S. aureus subsp. aureus (ATCC ${ }^{\bullet} 25923^{\mathrm{Tm}}$ ), S. pseudintermedius (LMG 22219) and S. intermedius (ATCC $29663^{\mathrm{ms}}$ ) were included. Isolates were defined as resistant or susceptible to fusidic acid using EUCAST breakpoints [21]; chlorhexidine breakpoints remain unreported.

\section{Identification of resistance genes and mutations}

Extraction of DNA was performed using a commercial purification kit (Bacterial Genomic DNA Purification kit, Edge BioSystems, Gaithersburg, MD, U.S.A). Each isolate's DNA was screened by PCR for the presence of fusC [34], fusD [34], qacA/B [71] and smr [72] using primers and methods as previously described. To detect fus $B$, a previously described PCR reaction [55] was optimised by the addition of $1.5 \mathrm{mM} \mathrm{MgCl} 2$ to the PCR mastermix (total $16.5 \mathrm{mM} \mathrm{MgCl} 2$ ).

In isolates with fusidic acid MIC $\geq 64 \mathrm{mg} / \mathrm{L}$, fus $A$ and fusE were amplified by PCR and then sequenced using the Sanger method (Source BioScience, Nottingham, U.K.) to identify mutations. A previously described method was used for PCR amplification of fusE [33]. The PCR for amplification of fusA [34] was optimised by increasing the elongation time from 2 to $3 \mathrm{~min}$. Four forward and four reverse primers, comprising six custom designed using the $S$. pseudintermedius ED99 genome sequence [35], and two previously described primers [34] were used for sequencing of the complete gene (Table 3). Nucleotide and translated amino acid sequences were aligned to control S. aureus (ATCC 29663 ${ }^{\mathrm{Tw}}$ ) and S. (pseud)intermedius (ATCC 25923 ${ }^{\mathrm{mm}}$, LMG 22219) fusA / fusE sequences using EMDL-EBI Clustal Omega Multiple Sequence Alignment Tool [73] and BLAST analyses (https:// blast.ncbi.nlm.nih.gov/Blast.cgi).

Table 5 Geographical origin of canine-derived staphylococci used in this study

\begin{tabular}{|c|c|c|c|c|c|c|}
\hline Geographical location & South-East U.K. ${ }^{a}$ & North U.K. & Germany $^{c}$ & Finland $^{d}$ & U.S.A. ${ }^{e}$ & Total \\
\hline MRSP & 47 & 49 & 24 & 49 & 50 & 219 \\
\hline FA-R MRSP & 0 & 0 & 0 & 40 & 0 & 40 \\
\hline MSSP & $44^{f}$ & 50 & 24 & 50 & 51 & 219 \\
\hline MRSA & 50 & 0 & 0 & 0 & 0 & 50 \\
\hline MSSA & 50 & 0 & 0 & 0 & 0 & 50 \\
\hline Total & 191 & 99 & 48 & 139 & 101 & 578 \\
\hline
\end{tabular}

MRSP methicillin-resistant S. pseudintermedius, FA-R fusidic acid resistant as defined by disk diffusion testing, MSSP methicillin-sensitive $S$. pseudintermedius, MRSA methicillin-resistant $S$. aureus, MSSA methicillin-sensitive $S$. aureus

All of clinical origin except ${ }^{f}$ which are of clinical $(n=3)$ and carriage $(n=41)$ origin

From the authors' collections: ${ }^{\mathrm{a}} \mathrm{SMF}, \mathrm{RB}, \mathrm{AL} ;{ }^{\mathrm{b}} \mathrm{DT} ; \mathrm{VMS} ;{ }^{\mathrm{c}} \mathrm{AL} ;{ }^{\mathrm{d}} \mathrm{MR}, \mathrm{TG}$; ${ }^{\mathrm{e}} \mathrm{SCR}, \mathrm{KO}$ 
Positive controls for each PCR comprised DNA extracts from strains carrying the desired genes. These were fusA/ fusE, S. aureus subsp. aureus [ATCC $25923^{\mathrm{max}}$ ] and S. intermedius [ATCC ${ }^{\circ} 29663^{\mathrm{m}}$ ]; fusB, S. aureus B30 [74]; fusC, $S$. aureus MSSA 476 [75]; fusD, S. saprophyticus subsp. saprophyticus [ATCC $15305^{\mathrm{mm}}$ ]; qacA/B, S. aureus Mu50 [76]; smr, S. aureus E37 [74]).

\section{Statistical analysis}

The MICs (dependent variable) for fusidic acid and chlorhexidine were compared between MRSP and MSSP (independent variables) within each geographical region using the Kruskal-Wallis test. Since MRSP and MSSP MICs did not vary within any of the regions, S. pseudintermedius MICs (dependent variable) were subsequently compared between regions (independent variable) using the Kruskal-Wallis tests with post hoc comparisons using Mann-Whitney U-tests with Holm-Bonferroni adjustments. These statistical analyses were performed using SPSS version 21 (IBM UK Ltd., Portsmouth, U.K.), with $P<0.05$ denoting significance.

\section{Abbreviations}

CHX: Chlorhexidine; FA: Fusidic acid; MIC: Minimum inhibitory concentration; MR: Methicillin-resistant; MS: Methicillin-susceptible; NUK: North U.K.; PCR: Polymerase chain reaction; PFGE: pulsed-field gel electrophoresis; SA: Staphylococcus aureus; SEUK: South-East U.K.; SP: Staphylococcus pseudintermedius

\section{Acknowledgements}

The authors thank the following scientists for donating isolates: Louise Kime (control isolate), Stephen Steen (some North U.K. isolates), Andrew Waller and Bernadette Legett (some South-East U.K. isolates).

The results from this study were presented at the European Society / College of Veterinary Dermatology Annual Congress, Lausanne, Switzerland September 2017. Vet Dermatol 2017; 28: 541 (Abstract).

\section{Funding}

SMF and this study were funded by a Biotechnology and Biological Sciences Research Council (Swindon, U.K.; BBSRC) industrial CASE scholarship in partnership with Dechra Veterinary Products Limited (Shropshire, U.K.; grant number BB/K011952/1). Design of the study; collection, analysis, and interpretation of data; and writing the manuscript was undertaken independently of the funding body.

\section{Availability of data and materials}

All data generated or analysed during this study are included in this published article.

\section{Authors' contributions}

SMF, RB and AL conceived, designed and executed the study, and analysed the data. AL, MR, TG, SCR, KO, DT, VMS collected, speciated and provided clinical staphylococcal isolates for testing. JAL conceived and supervised analysis and interpretation of gene sequencing. All authors participated in writing, and approved the final manuscript.

\section{Ethics approval and consent to participate}

Not applicable.

\section{Consent for publication}

Not applicable.

\section{Competing interests}

The authors' group (Royal Veterinary College) has received funding from Dechra Veterinary Products Limited (Shropshire, U.K.) in support of laboratory research and clinical teaching of undergraduate and postgraduate students.

\section{Publisher's Note}

Springer Nature remains neutral with regard to jurisdictional claims in published maps and institutional affiliations.

\section{Author details}

'Department of Clinical Sciences and Services, Royal Veterinary College, Hawkshead Lane, North Mymms, Hatfield, Hertfordshire AL9 7TA, UK.

${ }^{2}$ Department of Equine and Small Animal Medicine, Faculty of Veterinary Medicine, University of Helsinki, P.O. Box 57, 00014 Helsinki, Finland.

${ }^{3}$ Department of Pathobiology, School of Veterinary Medicine, University of Pennsylvania, 3850 Spruce Street, Philadelphia, PA 19104, USA. ${ }^{4}$ Institute of Veterinary Science, University of Liverpool, Chester High Road, Neston CH64 7TE, UK. Institute of Infection and Immunity, St George's, University of London, Cranmer Terrace, London SW17 ORE, UK.

Received: 16 July 2018 Accepted: 1 April 2019

Published online: 25 April 2019

\section{References}

1. Lloyd D. Bacterial skin diseases. In: Miller WH, Griffin CE, Campbell KL, editors. Muller and Kirk's Small Animal Dermatology, 7th ed. St Louis: Saunders-Elsevier; 2013. p. 184-234.

2. Loeffler A, Linek M, Moodley A, Guardabassi L, Sung JML, Winkler M, Weiss R, Lloyd DH. First report of multiresistant, mecA-positive Staphylococcus intermedius in Europe: 12 cases from a veterinary dermatology referral clinic in Germany. Vet Dermatol. 2007;18(6):412-21.

3. Gortel K, Campbell KL, Kakoma I, Whittem T, Schaeffer DJ, Weisiger RM. Methicillin resistance among staphylococci isolated from dogs. Am J Vet Res. 1999;60(12):1526-30

4. Hillier A, Lloyd DH, Weese JS, Blondeau JM, Boothe D, Breitschwerdt E, Guardabassi L, Papich MG, Rankin S, Turnidge JD, Sykes JE. Guidelines for the diagnosis and antimicrobial therapy of canine superficial bacterial folliculitis (antimicrobial guidelines working Group of the International Society for companion animal infectious diseases). Vet Dermatol. 2014;25(3): 163-e43.

5. Summers JF, Hendricks A, Brodbelt DC. Prescribing practices of primary-care veterinary practitioners in dogs diagnosed with bacterial pyoderma. BMC Vet Res. 2014:10:240

6. Joint Formulary Committee. MRSA Management. In: British National Formulary. London: BMJ Group and Pharmaceutical Press; 2018. Available from: https://bnf.nice.org.uk/treatment-summary/mrsa.html. Accessed 15 Apr 2018.

7. Atalay B, Ergin F, Cekinmez M, Caner H, Altinors N. Brain abscess caused by Staphylococcus intermedius. Acta Neurochir. 2005;147(3):347-8.

8. Kempker R, Mangalat D, Kongphet-Tran T, Eaton M. Beware of the pet dog: a case of Staphylococcus intermedius infection. Am J Med Sci. 2009:338(5): 425-7.

9. Chuang CY, Yang YL, Hsueh PR, Lee PI. Catheter-related bacteremia caused by Staphylococcus pseudintermedius refractory to antibiotic-lock therapy in a hemophilic child with dog exposure. J Clin Microbiol. 2010;48(4):1497-8.

10. Somayaji R, Priyantha MA, Rubin JE, Church D. Human infections due to Staphylococcus pseudintermedius, an emerging zoonosis of canine origin: report of 24 cases. Diagn Microbiol Infect Dis. 2016;85(4):471-6.

11. Lozano C, Rezusta A, Ferrer I, Pérez-Laguna V, Zarazaga M, Ruiz-Ripa L, Revillo MJ, Torres C. Staphylococcus pseudintermedius human infection cases in Spain: dog-to-human transmission. Vector Borne Zoonotic Dis. 2017;17(4): 268-70.

12. Harvey RG, Marples RR, Noble WC. Nasal carriage of Staphylococcus intermedius in humans in contact with dogs. Microb Ecol Health D. 1994; 7(4):225-7.

13. Guardabassi L, Loeber M, Jacobson A. Transmission of multiple antimicrobial-resistant Staphylococcus intermedius between dogs affected by deep pyoderma and their owners. Vet Microbiol. 2004;98(1):23-7.

14. Paul NC, Moodley A, Ghibaudo G, Guardabassi L. Carriage of methicillinresistant Staphylococcus pseudintermedius in small animal veterinarians: 
indirect evidence of zoonotic transmission. Zoonoses Public Health. 2011; 58(8):533-9.

15. Hanselman BA, Kruth SA, Rousseau J, Scott WJ. Coagulase positive staphylococcal colonization of humans and their household pets. Can Vet J. 2009;50(9):954-8

16. Walther B, Hermes J, Cuny C, Wieler LH, Vincze S, Elnaga YA, Stamm I, Kopp PA, Kohn B, Witte W, Jansen A, Conraths FJ, Semmler T, Eckmanns T, LübkeBecker A. Sharing more than friendship - nasal colonization with coagulasepositive staphylococci (CPS) and co-habitation aspects of dogs and their owners. PLoS One. 2012; (4):e35197.

17. Mueller RS, Bergvall K, Bensignor E, Bond R. A review of topical therapy for skin infections with bacteria and yeast. Vet Dermatol. 2012;23(4):330-e62.

18. Brown EM, Thomas P. Fusidic acid resistance in Staphylococcus aureus isolates. Lancet. 2002;359(9308):803.

19. Block C, Furman M. Association between intensity of chlorhexidine use and micro-organisms of reduced susceptibility in a hospital environment. J Hosp Infect. 2002;51(3):201-6.

20. Williamson DA, Monecke $S$, Heffernan $H$, Ritchie SR, Roberts SA, Upton A, Thomas MG, Fraser JD. High usage of topical fusidic acid and rapid clonal expansion of fusidic acid-resistant Staphylococcus aureus: a cautionary tale. Clin Infect Dis. 2014;59(10):1451-4.

21. EUCAST (European Committee on Antimicrobial Susceptibility Testing). 2017. Breakpoint tables for interpretation of MICs and zone diameters. Version 7.1. http://www.eucast.org/fileadmin/src/media/PDFs/EUCAST_files/ Breakpoint_tables/v_7.1_Breakpoint_Tables.pdf. Accessed 18 Feb 2018.

22. Ellington MJ, Reuter S, Harris SR, Holden MTG, Cartwright EJ, Greaves D, Gerver SM, Hope R, Brown NM, Török ME, Parkhill J, Köser CU, Peacock SJ, Emergent and evolving antimicrobial resistance cassettes in communityassociated fusidic acid and meticillin-resistant Staphylococcus aureus. Int J Antimicrob Agents. 2015;45(5):477-84.

23. Wang JT, Sheng WH, Wang JL, Chen D, Chen ML, Chen YC, Chang SC. Longitudinal analysis of chlorhexidine susceptibilities of nosocomial methicillin-resistant Staphylococcus aureus isolates at a teaching hospital in Taiwan. J Antimicrob Chemother. 2008;62(3):514-7.

24. Smith $\mathrm{K}$, Gemmell CG, Hunter IS. The association between biocide tolerance and the presence or absence of gac genes among hospital-acquired and community-acquired MRSA isolates. J Antimicrob Chemother. 2008;61(1):78-84.

25. Lee AS, Macedo-Vinas M, François P, Renzi G, Schrenzel J, Vernaz N, Pittet D, Harbarth S. Impact of combined low-level mupirocin and genotypic chlorhexidine resistance on persistent methicillin-resistant Staphylococcus aureus carriage after decolonization therapy: a case-control study. Clin Infect Dis. 2011;52(12):1422-30.

26. O'Neill AJ, Chopra I. Molecular basis of fusB-mediated resistance to fusidic acid in Staphylococcus aureus. Mol Microbiol. 2006;59(2):664-76.

27. Lannergård J, Norström T, Hughes D. Genetic determinants of resistance to fusidic acid among clinical bacteremia isolates of Staphylococcus aureus. Antimicrob Agents Chemother. 2009;53(5):2059-65.

28. Farrell DJ, Castanheira M, Chopra I. Characterization of global patterns and the genetics of fusidic acid resistance. Clin Infect Dis. 2011;52(7):S487-92.

29. O'Neill AJ, McLaws F, Kahlmeter G, Henriksen AS, Chopra I. Genetic basis of resistance to fusidic acid in staphylococci. Antimicrob Agents Chemother. 2007;51(5):1737-40.

30. Besier S, Ludwig A, Brade V, Wickelhaus TA. Molecular analysis of fusidic acid resistance in Staphylococcus aureus. Mol Microbiol. 2003;47(2):463-9.

31. Norström T, Lannergård J, Hughes D. Genetic and phenotypic identification of fusidic acid-resistant mutants with the small-colony-variant phenotype in Staphylococcus aureus. Antimicrob Agents Chemother. 2007;51 (12):4438-46.

32. Castanheira M, Watters AA, Mendres RE, Farrell DJ, Jones RN. Occurrence and molecular characterization of fusidic acid resistance mechanisms among Staphylococcus spp. from European countries (2008). J Antimicrob Chemother. 2010;65(7):1353-8.

33. Castanheira M, Watters AA, Bell JM. JD Turnidge, Jones RN. Fusidic acid resistance rates and prevalence of resistance mechanisms among Staphylococcus spp. isolated in North America and Australia, 2007-2008. Antimicrob Agents Chemother. 2010;54(9):3614-7.

34. Chen H-J, Hung W-C, Tseng S-P, Tsai J-C, Hsueh P-R, Teng L-J. Fusidic acid resistance determinants in Staphylococcus aureus clinical isolates. Antimicrob Agents Chemother. 2010;54(12):4985-91.

35. McCarthy AJ, Harrison EM, Stanczak-Mrozek K, Leggett B, Waller A, Holmes MA, Lloyd DH, Lindsay JA, Loeffler A. Genomic insights into the rapid emergence and evolution of MDR in Staphylococcus pseudintermedius. J Antimicrob Chemother. 2015;70(4):997-1007.
36. Worthing KA, Marcus A, Abraham S, Trott DJ, Norris JM. Qac genes and biocide tolerance in clinical veterinary methicillin-resistant and methicillinsusceptible Staphylococcus aureus and Staphylococcus pseudintermedius. Vet Microbiol. 2018;216:153-8.

37. Sheng WH, Wang JT, Lauderdale TL, Weng C-M, Chen D, Chang S-C. Epidemiology and susceptibilities of methicillin-resistant Staphylococcus aureus in Taiwan: emphasis on chlorhexidine susceptibility. Diagn Micr Infec Dis. 2009;63(3):309-13.

38. McDanel JS, Murphy CR, Diekema DJ, Quan V, Kim DS, Peterson EM, Evans KD, Tan GL, Hayden MK, Huang SS. Chlorhexidine and mupirocin susceptibilities of methicillin-resistant Staphylococcus aureus from colonized nursing home residents. Antimicrob Agents Chemother. 2013;57(1):552-8.

39. Noguchi N, Hase M, Kitta M, Sasatsu M, Deguchi K. Kono Megumi. Antiseptic susceptibility and distribution of antiseptic-resistance genes in methicillinresistant Staphylococcus aureus. FEMS Microbiol Lett. 1999;172(2):247-53.

40. McGann P, Kwak YI, Summers A, Cummings JF, Waterman PE, Lesho EP. Detection of gacA/B in clinical isolates of methicillin-resistant Staphylococcus aureus from a regional healthcare network in the eastern United States. Infect Control Hosp Epidemiol. 2011;32(11):1116-9.

41. McGann P, Milillo M, Kwak YI, Quintero R, Waterman PE, Lesho E. Rapid and simultaneous detection of the chlorhexidine and mupirocin resistance genes qacA/B and mupA in clinical isolates of methicillin-resistant Staphylococcus aureus. Diagn Microbiol Infect Dis. 2013;77(3):270-2.

42. Nakaminami H, Noguchi N, Nishijima S, Kurokawa I, Hiromu SO, Sasatsu M. Transduction of the plasmid encoding antiseptic resistance gene $9 a c B$ in Staphylococcus aureus. Biol Pharm Bull. 2007;30(8):1412-5.

43. Naidoo J, Lloyd DH. Transmission of genes between staphylococci on skin. In: Woodbine M, editor. Antimicrobials and agriculture. London: Butterworths; 1984. p. 282-95.

44. Wisplinghoff H, Rosato AE, Enright MC, Noto M, Craig W, Archer GL. Related clones containing SCCmec type IV predominate among clinically significant Staphylococcus epidermidis isolates. Antimicrob Agents Chemother. 2003; 47(11):3574-9.

45. Hanssen AM, Kjeldsen G, Sollid JU. Local variants of staphylococcal cassette chromosome mec in sporadic methicillin-resistant Staphylococcus aureus and methicillin-resistant coagulase-negative staphylococci: evidence of horizontal gene transfer? Antimicrob Agents Chemother. 2004;48(1):285-96.

46. Rolo J, Worning P, Nielsen JB, Bowden R, Bouchami O, Damborg P, Guardabassi L, Perreten V, Tomasz A, Westh H, de Lencastre H, Miragaia M. Evidence for the evolutionary steps leading to mecA-mediated $\beta$-lactam resistance in staphylococci. PLoS Genet. 2017;13(4):e1006674.

47. Wielders $C L$, Vriens MR, Brisse $S$, de Graaf-Miltenburg LA, Troelstra A, Fleer A, Schmitz FJ, Verhoef J, Fluit AC. In-vivo transfer of mecA DNA to Staphylococcus aureus. Lancet. 2001;357(9269):1674-5.

48. Clark SM, Loeffler A, Schmidt VM, Chang Y-M, Wilson A, Timofte D, Bond R. Interaction of chlorhexidine with trisEDTA or miconazole in vitro against canine meticillin-resistant and susceptible Staphylococcus pseudintermedius isolates from two UK regions. Vet Dermatol. 2016;27(5):340-e84.

49. Clark SM, Loeffler A, Bond R. Susceptibility in vitro of canine methicillinresistant and -susceptible staphylococcal isolates to fusidic acid, chlorhexidine and miconazole: opportunities for topical therapy of canine superficial pyoderma. J Antimicrob Chemoth. 2015;70(7):2048-52.

50. Besier S, Ludwig A, Brade V, Wickelhaus TA. Compensatory adaptation to the loss of biological fitness associated with acquisition of fusidic acid resistance in Staphylococcus aureus. Antimicrob Agents Chemother. 2005; 49(4):1426-31.

51. Ledda A, Price JR, Cole K, Llewelyn MJ, Kearns AM, Crook DW, Paul J, Didelot X. Re-emergence of methicillin susceptibility in a resistant lineage of Staphylococcus aureus. J Antimicrob Chemother. 2017;72(1):1285-8.

52. Lee SM, Ender M, Adhikari R, Smith JM, Berger-Bächi B, Cook GM. Fitness cost of staphylococcal cassette chromosome mec in methicillin-resistant Staphylococcus aureus by way of continuous culture. Antimicrob Agents Chemother. 2007;51(4):1497-9.

53. Loeffler A, Boag AK, Sung J, Lindsay JA, Guardabassi L, Dalsgaard A, Smith H, Stevens KB, Lloyd DH. Prevalence of methicillin-resistant Staphylococcus aureus among staff and pets in a small animal referral hospital in the UK. J Antimicrob Chemother. 2005;56(4):692-7.

54. Roberts GA, Houston PJ, White JH, Chen K, Stephanou AS, Cooper LP, Dryden DT, Lindsay JA. Impact of target site distribution for type I restriction enzymes on the evolution of methicillin-resistant Staphylococcus aureus (MRSA) populations. Nucleic Acids Res. 2013;41(15):7472-84. 
55. O'Neill AJ, Larsen AR, Henriksen AS, Chopra I. A fusidic acid-resistant epidemic strain of Staphylococcus aureus carries the fusB determinant, whereas fusA mutations are prevalent in other resistant isolates. Antimicrob Agents Chemother. 2004;48(9):3594-7.

56. Sidhu S, Heir E, Leegaard T, Wiger K, Holck A. Frequency of disinfectant resistance genes and genetic linkage with $\beta$-lactamase transposon tn552 among clinical staphylococci. Antimicrob Agents Chemother. 2002;46(9):2797-803.

57. Mayer S, Boos M, Beyer A, Fluit AC, Schmitz F-J. Distribution of the antiseptic resistance genes qacA, qacB and qacC in 497 methicillin-resistant and susceptible European isolates of Staphylococcus aureus. J Antimicrob Chemother. 2001;47(6):896-7.

58. Noguchi N, Suwa J, Narui K, Sasatsu M, Ito T, Hiramatsu K, Song J-H. Susceptibilities to antiseptic agents and distribution of antiseptic-resistance genes qacA $B$ and $s m r$ of methicillin-resistant Staphylococcus aureus isolated in Asia during 1998 and 1999. J Med Microbiol. 2005:54(Pt 6):557-65.

59. Vali L, Davies SE, Lai LLG, Dave J, Amyes SGB. Frequency of biocide resistance genes, antibiotic resistance and the effect of chlorhexidine exposure on clinical methicillin-resistant Staphylococcus aureus isolates. J Antimicrob Chemother. 2008;61(3):524-32

60. Skovgaard S, Larsen MH, Nielsen LN, Skov RL, Wong C, Westh H, Ingmer H. Recently introduced gacA/B in Staphylococcus epidermidis do not increase chlorhexidine MIC/MBC. J Antimicrob Chemother. 2013;68(10):2226-33.

61. Frosini SM, Bond R, Loeffler A, Larner J. Opportunities for topical antimicrobial therapy: permeation of canine skin by fusidic acid. BMC Vet Res. 2017;13(1):345.

62. EUCAST (European Committee on Antimicrobial Susceptibility Testing) Fusidic acid: Rationale for the clinical breakpoints, version 1.0, 2010. http:// www.eucast.org/fileadmin/src/media/PDFs/EUCAST_files/Rationale_ documents/Fusidic_acid_rationale_1.0_2010_Oct.pdf. Accessed 29 June 2018.

63. Papich MG. Antimicrobials, susceptibility testing, and minimum inhibitory concentrations (MIC) in veterinary infection treatment. Vet Clin North Am Small Anim Pract. 2013;43(5):1079-89.

64. National Institute of Health and Welfare. 2015 Vanha FiRe-standardi. Versio 6. https://thl.fi/attachments/Fire/liite_3a_erh_sir_taulukko.pdf. Accessed 15 Apr 2018.

65. Skov E, Frimodt-Möller N, Espersen F. Correlation of MIC methods and tentative interpretive criteria for disk diffusion susceptibility testing using NCCLS methodology for fusidic acid. Diagn Microbiol Infect Dis. 2001;40(3):111-6.

66. Barrow GI, Feltham RKA. Characters of gram-positive bacteria. In: Barrow Gl, Feltham RKA, editors. Cowan and Steel's manual for the identification of medical Bacteria. 3rd ed. Cambridge: Cambridge University Press; 2003. p. 52-7.

67. Brakstad OG, Aasbakk K, Maeland JA. Detection of Staphylococcus aureus by polymerase chain reaction amplification of the nuc gene. J Clin Microbiol. 1992;30(7):1654-60.

68. Brakstad OG, Maeland JA, Tveten Y. Multiplex polymerase chain reaction for detection of genes for Staphylococcus aureus thermonuclease and methicillin resistance and correlation with oxacillin resistance. APMIS. 1993;101(9):681-8.

69. Becker K, von Eiff C, Keller B, Brück M, Etienne J, Peters G. Thermonuclease gene as a target for specific identification of Staphylococcus intermedius isolates: use of a PCR-DNA enzyme immunoassay. Diagn Microbiol Infect Dis. 2005;51(4):237-44.

70. Clinical and Laboratory Standards Institute. Performance Standards for Antimicrobial Disk and Dilution Susceptibility Tests for Bacteria Isolated From Animals_Fourth Edition: Approved Standard VET01-A4. Wayne: CLSI; 2013.

71. Rouch DA, Cram DS, DiBerardino D, Littlejohn TG, Skurray RA. Effluxmediated antiseptic resistance gene gacA from Staphylococcus aureus: common ancestry with tetracycline- and sugar-transport proteins. Mol Microbiol. 1990;4(12):2051-62.

72. McNeil JC, Hulten KG, Kaplan SL, Mason EO. Decreased susceptibilities to retapamulin, mupirocin, and chlorhexidine among Staphylococcus aureus isolates causing skin and soft tissue infections in otherwise healthy children. Antimicrob Agents Chemother. 2014;58(5):878-83.

73. Li W, Cowley A, Uludag M, Gur T, McWilliam H, Squizzato S, Park YM, Buso $\mathrm{N}$, Lopez R. The EMBL-EBI bioinformatics web and programmatic tools framework. Nucleic Acids Res. 2015;45(W1):W580-4.

74. Knight GM, Budd EL, Whitney L, Thornley A, Al-Ghusein H, Planche T, Lindsay JA. Shift in dominant hospital-associated methicillin-resistant Staphylococcus aureus (HA-MRSA) clones over time. J Antimicrob Chemother. 2012;67(10):2514-22.

75. Holden MT, Feil EJ, Lindsay JA, Peacock SJ, Day NP, Enright MC, Foster TJ, Moore CE, Hurst L, Atkin R, Barron A, Bason N, Bentley SD, Chillingworth C, Chillingworth
T, Churcher C, Clark L, Corton C, Cronin A, Doggett J, Dowd L, Feltwell T, Hance Z, Harris B, Hauser H, Holroyd S, Jagels K, James KD, Lennard N, Line A, Mayes R, Moule S, Mungall K, Ormond D, Quail MA, Rabbinowitsch E, Rutherford K, Sanders M, Sharp S, Simmonds M, Stevens K, Whitehead S, Barrell BG, Spratt BG, Parkhill J. Complete genomes of two clinical Staphylococcus aureus strains: evidence for the rapid evolution of virulence and drug resistance. Proc Natl Acad Sci U.S.A. 2004;101(26):9786-91.

76. Kuroda M, Ohta T, Uchiyama I, Baba T, Yuzawa H, Kobayashi I, Cui L, Oguchi A, Aoki K, Nagai Y, Lian J, Ito T, Kanamori M, Matsumaru H, Maruyama A, Murakami H, Hosoyama A, Mizutani-Ui Y, Takahashi NK, Sawano T, Inoue R, Kaito C, Sekimizu K, Hirakawa H, Kuhara S, Goto S, Yabuzaki J, Kanehisa M, Yamashita A, Oshima K, Furuya K, Yoshino C, Shiba T, Hattori M, Ogasawara $\mathrm{N}$, Hayashi $\mathrm{H}$, Hiramatsu K. Whole genome sequencing of meticillin-resistant Staphylococcus aureus. Lancet. 2001;357(9264):1225-40.

\section{Ready to submit your research? Choose BMC and benefit from:}

- fast, convenient online submission

- thorough peer review by experienced researchers in your field

- rapid publication on acceptance

- support for research data, including large and complex data types

- gold Open Access which fosters wider collaboration and increased citations

- maximum visibility for your research: over $100 \mathrm{M}$ website views per year

At BMC, research is always in progress.

Learn more biomedcentral.com/submissions 